it would be unreasonable to strive for it. Man will always be faced with more or less important diseases and disorders caused by the environment in which he exists, and which, to a large extent, he has created. On the other hand, there is very much that could be done to correct disorders, to control diseases, and to raise the present general level of health. The costs which this would involve should be seen in perspective against the benefits in having as healthy a community as possible".

\section{Bausch and Lomb Metallographs}

The 'Dynazoom' series of metallographs recently introduced by Bausch and Lomb consists of a versatile set of bench-type models suitable for general metallurgical work both in industry and in schools and colleges. The instrument is based on the inverted microscope principle and there are models for both visual and photo. graphic work, using bright field, dark field or polarized light illumination. The exclusive 'Dynazoom' system permits extended continuous magnification ranging from $\times 25$ to $\times 800$, at a twist of a dial. With accessory optical components the range can be extended to $\times 3,750$. The optical elements are enclosed in a 'Power Pod' housing for protection against dirt and dust. The housing can be removed from the main body of the instrument and a different 'Pod' (monocular or binocular) substituted. 'The 'Power Pod' bodies are inclined, providing a comfortable viewing angle for prolonged examination and can be rotated through a full $360^{\circ}$. A unique feature of the metallograph is a built-in rotating reticle turret with six apertures to accommodate a variety of measuring reticles which can be quickly and easily inserted or removed through a door in the bottom of the instrument. Photomicrography is a simple procedure. The photobinocular zoom body can be obtained separately and is directly interchangeable with any other zoom body. Four cameras are at present available: $35 \mathrm{~mm}, 2 \frac{1}{4}$ in. $\times 3 \frac{1}{4}$ in. 'Polaroid', and the Bausch and Lomb ' $L$ ' and ' $N$ ' models. A green filter with a peak at $500 \mathrm{~m} \mu$ is standard on all instruments. There are provisions for both black-and-white and colour reproduction of metallic structure, and colour-compensating, colour-balancing and neutral-density filters are also available.

\section{Lalor Foundation Grants for 1965}

The Lalor Foundation has announced the programme of awards for 1965, which it is offering for support of research on the fundamental biochemical and physiological mechanisms concerned with fertility and the early stages of reproduction in various forms of life. The objectives are to further the knowledge and understanding of the basic phenomena involved and to extend and develop the possibilities for effective regulation and control. The awards are opon to all nationalities, and may range up to 8,000 dollars a year, depending on the scope and duration of the projects approved. Preference will be given to younger members of university and college faculties and staff, with an upper age-limit of forty-one years. The work may be carried on at the applicant's own institution or elsewhere. The Foundation will also grant post-doctorate summer or short-term research awards at the Marine Biological Laboratory at Woods Hole, Mass., or elsewhere for appropriate projects in the fields specified. These awards will normally not exceed 1,150 dollars for a single man or a woman, 1,350 dollars for a married man working at his home institution, and 1,500 dollars for a married man with principal programme at another institution. Further information and application forms can be obtained from the Lalor Foundation, 4400 Lancaster Pike, Wilkington, Delaware, 19805. The final date for receipt of executed application forms, complete with supporting data, is January 15, 1965. Notification of appointment will be on or before March 15.

\section{North of England Soils Discussion Group}

A Discussion group is being formed covering broadly the North of England to further the invostigation of all aspects of the soil. Membership is invited from individuals or educational and vocational bodies that have an interest in the soil. It is intended to embrace all aspects of the investigation of the soil, including the biological, cultural, physical and economic, as well as the purely pedalogical, and its bearing on land uso. An annual moeting will be held, to include a field excursion, and a paper-reading session with discussion, probably in September. A spocific topic will be the main fuature of each meeting, and will largely determine the locality to be visited. Further information concerning membership and meetings can be obtained from: Dr. V. B. Proudfoot, Department of Geography, University of Durham; Mr. G. D. Ashley, Soil Survey of Englard and Wales, Kenton Bar, Newcastle upon Tyne; Mr. P. J. A. Howard, Nature Conservancy, Grange-over-Sands, Lancashire; or from the secretary, Mr. H. T. Davies, Soil Chemistry Department, National Agricultural Advisory Service, Govornment Buildings, Lawnswood, Ler.ds, 16.

The first meeting of the North of England Soils Discussion Group on "Soils and Land Use Problems in the Marginal Farming Areas of the Pennine Foothills" will be held in Lancashire during September 28-30. Further information can be obtained from Mr. H. T. Davies.

\section{Announcements}

The President's Lecture of the Institution of Electronics, entitled "The Vanishing Electron", will be delivered by Dr. R. C. Jennison at the Manchester College of Science and Technology on October 3. Further information and tickets can be obtained from the General Secretary, Institution of Electronics, 78 Shaw Road, Rochdale, Lancs.

THE fourth annual meeting of the American Society for Cell Biology will be held in Cleveland, Ohio, during November 11-13. The programme will include a symposium on "The Structure, Function and Origin of Biological Membranes". Further information can be obtained from Dr. D. Green, Institute for Enzyme Research, 1,170 University Avenue, Madison 6, Wisconsin.

A symposium on "Models for the Perception of Speech and Visual Form", sponsored by the Data Sciences Laboratory of the Air Force Cambridge Research Laboratory, will bo held in Boston during November 11-14. Further information can be obtained from Mr. G. A. Cushman, Wentworth Institute, 550 Huntington Avenue, Boston, Massachusetts 02115.

A SYMPOSIUM on "The Use of Radioisotopes in Animal Nutrition and Physiology", sponsored by the International Atomic Energy Agency and the Food and Agriculture Organization, will be held in Prague during November 23-27. Topies under discussion will include: physiology and biochemistry of milk secretion; metabolism and requirement of trace elements including magnesium; the influence of environmental factors on animal production and reproduction. Further information can be obtained from IAEA/FAO Symposium Secretariat, Kärntnerring 11, Vienna I.

A short course on "Solution Properties of Polymers", arranged by the Department of Chemical Technology of the Bradford Institute of Technology, will be held in the Institute during November 13-14. The course, which is intended primarily for graduates, will include lectures on: viscosities of dilute solutions; fractionation; determination of molecular weight distribution; solution properties in relation to polymer properties; newer methods of molecular weight determination. Further information and forms of application can be obtained from the Registrar, Bradford Institute of Technology, Bradford 7. 